\title{
Comprehensive assessment of the health and physical development in martial arts athletes
}

\author{
Elena Katamanova ${ }^{1, *}$, Larisa Vasilieva ${ }^{1}$, Natalia Kuptsova $^{1}$, Irina Kodinets $^{1}$, Irina \\ Kudaeva $^{1}$, and Galina Sal'nikova ${ }^{1}$ \\ ${ }^{1}$ Federal State Budgetary Scientific Institution «East-Siberian Institute of Medical and Ecological \\ Research», 12 a microdistrict, 3, Angarsk, 665827, Russia
}

\begin{abstract}
Thirty three athletes' health (average age $-16.4 \pm 1.0$ years) were studied. Anthropometry and analysis of body composition, and load test were performed by the Hardware-software complex "ZdorovyeExpress" (Russia). Spirometry, electrocardiography, assessment of physical performance as per Harvard step test, and ultrasound scan of abdominal organs, blood biochemical indicators were also performed. It is established, examined athletes have medium level of harmony of development and high level of physical fitness. Harvard step test data showed that the vast majority of athletes have an adequate level of physical performance $(66.6 \%)$ with good recovery ability, and $33.4 \%$ - a very poor level of physical performance with a normal or slow recovery period after exercise. Assessing the cardiac singular index, the condition of the cardiovascular system in $82.6 \%$ surveyed was considered as optimal and in $17.3 \%$ examined as moderately increased. Spirometer indicators confirmed to the age norms. Ultrasound data of the abdominal organs showed the presence of disturbances in $24 \%$ of cases, while these disorders were manifested by diffuse liver echogenicity changes in $7 \%$ of cases and pathology of the gallbladder in $17 \%$ cases. The revealed changes in the health status of athletes require further research.
\end{abstract}

\section{Introduction}

The National Doctrine and the Federal program for the development of education highlight leading tasks and there is not only educational but the tasks of preserving, strengthening and development of the health of the younger generation, optimizing the educational process, and developing and implementing new health-saving technologies. At the same time, priority is given to the construction of indoor and outdoor sports complexes, summer sports grounds, development of tourism, and organization of tourist gatherings, mass sports and recreation events in the natural environment.

Currently, the issue of developing a new direction of large-scale testing in education concerning to monitor the physical development and physical fitness of schoolchildren and young athletes, is being discussed. Study results will be taken into account when building an all-Russian system for evaluating quality of education. The monitoring system should

\footnotetext{
*Corresponding author: katamanova_e_v@mail.ru
} 
have a clearly defined set of test exercises, questionnaires, and forms of submitted reporting documentation for all types of educational institutions. This will allow tracking the dynamics of indicators of physical development, physical and functional fitness of students; to conduct a comprehensive assessment of the organization of the educational institution to preserve and strengthen the health of all members of the educational process [1].

Sport challenges to the athlete both on a psychologically and physically level and in some cases exorbitant. The specific qualities - physical, technical, tactical, psychological and moral - are important to a particular sport. To achieve high results, the athlete has been training for many years with increasing training and competitive loads.

Martial arts athletes are motivated to develop qualities and skills such as strength, speed, agility, coordination, overall performance and endurance. These qualities are the basis for improving technical preparedness and tactical skills in the chosen sport [2].

Martial arts are a sport that is characterized by high energy expenditure when achieving very high intensity physical activity. Martial arts trainings allow developing all muscle groups, the cardiovascular and respiratory systems, and the musculoskeletal system. The competition is based on a competitive moment, which implies initially equal conditions for the wrestlers. There is a necessity to know the athletes' health level, their physical development and level of fitness for permission to high-intensity physical activity, and adequate choice of rival [3].

The theory of sports considers physical condition at least in three projections: health, physique and physiological functions. Physiological functions include motor function which means both technical readiness and the level of development of physical qualities. However, in the specialized literature and in practice, all these signs, although they are considered in interconnection, are most often of an independent and are studied separately. The concept of "diagnostics" is rare in the most studies devoted to control in sports. In fact, it has been replaced by the word "control", which, in addition to checking, has one more function - "the ability to recognize"; this is how diagnostics is translated from Greek. Diagnostics includes the theory and methods of determining the athletes' state and fitness level, as well as the principles of determining and constructing a diagnosis [4].

Statistically analyzed information accumulated over the years is the basis of diagnostics, which makes it possible to compare and evaluate the results of the last test with similar data from previous years. Sports and pedagogical diagnostics organically fit into the system of training athletes. It is aimed to obtain information (diagnosis) about the athletes' physical condition and special training.

One of the most important elements of the athletes' the training management system is complex control, which is understood as "a set of organizational measures for evaluating various aspects of athletes' fitness, the body's responses to training and competitive loads, the effectiveness of the training process, as well as taking into account adaptive rearrangements of athletes' body functions" [5].

Professional sports is a natural testing ground for identifying and testing human motor capabilities in conditions of activity close to extreme. Nowadays, it is possible to train professional athletes only within an integrated approach. One of the most important components of integrated training is the optimal organization of medical and biological support, which is impossible without a preliminary comprehensive assessment of the health of athletes.

Organization of medical and biological support is relevant due to martial arts are sports characterized by a non-constant, cyclical level of physical activity that depends on the specific conditions of competition and reaches a very high intensity [6]. The purpose of our study was to assess the health and physical development of martial artists to determine further recommendations for parents and coaches. 


\section{Materials and methods}

Thirty three martial arts athletes (average age $-16.4 \pm 1.0$ years, average sports experience 8.1 years $(2.0-12.0)$ ) were enrolled in the study. Anthropometry and analysis of body composition, load tests were used to characterize the level of health. Physical activity and energy costs were examined additionally.

Anthropometry and analysis of body composition, and load test were performed by the Hardware-software complex "Zdorovye-Express" (Russia). Body weight, height, carpal dynamometry, caliperometry, chest and head circumferences, blood pressure and pulse were assessed as per "Anthropometry" module. We performed Program assessment of the trophological status and nutritional status of the triceps and the shoulder muscles circumference per the skin-fat folds (SFF), the body component composition, calculation of the strength index and the cardiac singular index [4,7].

Harvard step test was used to determine physical performance assessed by the value of the Harvard step test index (HSTI), and the quality of the body's adaptation to the load was assessed by the type of reaction of the cardiovascular system. The kind of sport - martial arts - was taken into account assessing HSTI [8].

The respiratory function was analyzed using measurements of high-speed indicators of bronchial patency with using a portable spirometer, with the recording of flow-volume curve and results of measurement expressed as a percentage from the proper values.

A General blood analysis, levels of fibrinogen, alanine aminotransferase, aspartate aminotransferase, gamma-glutamyl transferase, creatinine in the blood using a biochemical photometer ("Cormay multy", Poland) was conducted.

Ultrasound scan of the abdominal organs was performed by Ultrasonic diagnostic system with accessories (GE Medical Systems Kretztenik Gmbh, Austria), System GE Healthcare Voluson E8 Expert using 4.5 MHz, $12 \mathrm{MHz}$ sensors.

Statistical processing was carried out with the program "STATISTICA. 6" (Stat Soft Inc., USA).

The obtained indicators in the group were compared with normative ones of the same age group.

Research were carry out in accordance with the requirements of biomedical ethics imposed by the Helsinki Declaration of the World Medical Association (2000) and Order of the Ministry of Health of the Russian Federation No. 266 (dated 19.06.2003) and did not infringe upon the right and did not endanger the well-being of the surveyed.

\section{Results}

Assessment of the harmony of development in the young athletes has an important role for assessing the athletes' physical health. Harmony of physical development divided into several levels. Summarizing the overall indicators - a centile estimate of weight, body length, chest circumference and head, fat fold thickness - it was found that the overwhelming majority of the examined athletes had an average level of the harmony of development (38.1\%), a high level and very high level at $23.81 \%$ and $19.05 \%$ accordingly. Moreover, there are also people with development below the average level $(9.5 \%)$.

One of the most important physiometric indicators is strength testing using hand-held dynamometry. The muscular strength of the hands characterizes the muscular development level and allows assessing the physical fitness level of the child [8, 9]. Evaluating dynamometry indicators, the following average values were obtained $39.9 \pm 5.9$ daN and $38.0 \pm 5.6 \mathrm{daN}$ on the right and the left hand accordingly. Simultaneously, $42.9 \%$ of the surveyed have the strength of the right hand is above the average for this age group (Figure 1 ), while the strength of the left hand is above the average and high level in $38.1 \%$ and 
$33.3 \%$ examined accordingly (Figure 2). The resulting data indicate a high level of physical development.

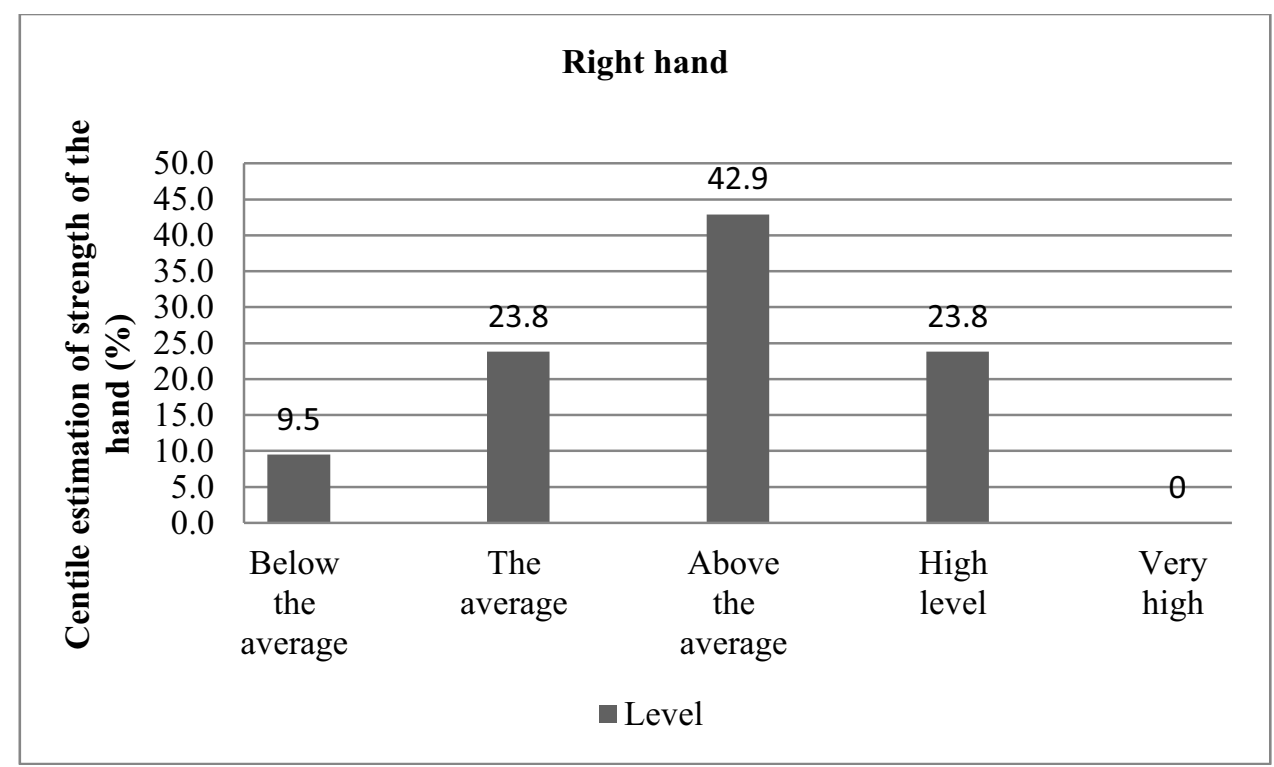

Fig. 1. Centile estimation of strength of the right hand

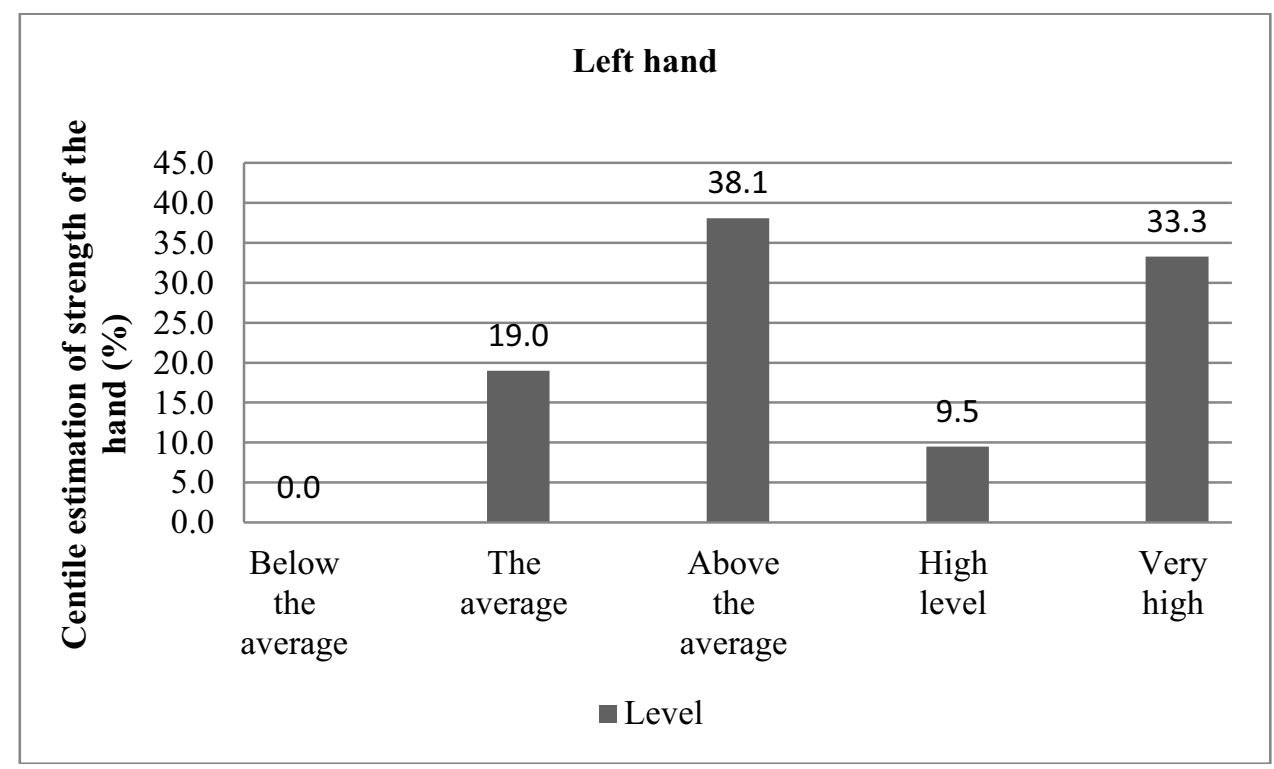

Fig. 2. Centile estimation of strength of the left hand

The level of physical performance as per the Harvard step test index (HSTI) and the quality of the body's adaptation to the load were also taken into account in assessing the functional state of athletes. According to the HSTI level, the overwhelming majority of athletes had an adequate level of physical performance with a good recovery period $(66.6 \%)$, and $33.4 \%$ had a very low level of physical performance with a normal or slow recovery period after the load. 
Assessing the cardiac singular index, the state of the cardiovascular system in $82.6 \%$ surveyed was considered as optimal and in $17.3 \%$ examined as moderately increased (Table 1).

Table 1. Cardiac singular index CV-SI in surveyed group (per 100 examined)

\begin{tabular}{|l|l|l|}
\hline $\begin{array}{l}\text { 0.56-optimal value of the Cardiac } \\
\text { index }\end{array}$ & 82.61 & Optimal \\
\hline $\begin{array}{l}0.66 \text {-optimal value of the Cardiac } \\
\text { index }\end{array}$ & 17.39 & Moderate increase \\
\hline
\end{tabular}

Non-traumatic health disorders in athletes through their professional activities are usually considered as pre-clinical functional disorders of different organs and systems, and also various acute and chronic diseases formed in the sport training process.

It should be noted that Sports medicine, not only diseases, but also various functional disorders of the cardiovascular system analyzes circumstantially. Changes detected via ECG, which in most cases do not appear in complaints and clinically, considered the functional states of the circulatory system. The bradycardia and normal blood pressure peculiarizes the most surveyed athletes. Perhaps this is due to the economization of muscle activity associated with the influence of long-term sports. A comparative analysis of the indicators of electrical activity of the heart showed that the majority examined individuals had normal ECG parameters. Changes in the form of episodic ventricular extrasystole were determined in younger athletes $-15.0 \%$ of them had sinus tachycardia, while the average heart rate was from 84 to $97 \mathrm{bpm}$. Signs of autonomic instability, which can be regarded as dynamic and possibly coming adaptation signs to physical exertion, were such as incomplete right bundle branch block, an impaired repolarization of metabolic nature $(2 \%$ of cases). Based on complaints, medical history and spirometry data, respiratory system disturbances were evaluated. The average vital capacity (VC) was $64 \%$ that corresponded to the age norms. The percentage of forced $\mathrm{VC}$ to the volume of exhaled air per $1 \mathrm{sec}^{*} 100$ (ratio of FEV1/FVC x 100), a modification of the Tiffeneau index, was reduced by $1.32 \%$ relatively the group norms, that indicates minor obstructive disturbances. At the same time, forced expiratory volume (FVC) of $25 \%$ (FEF 25) - the maximum expiratory flow of $25 \%$ FVC - was decreased of $1.2 \%$ relatively the group norms. 50\% FVC (FEF 50) was by figures close to the norm, and $75 \%$ FVC (FEF 75) - the maximum volumetric air velocity at the expiratory flow of $75 \%$ - was higher parameter values relatively group norms.

Some of the examined patients had changes in the General clinical blood test. Thus, hemoglobin level exceeded the reference values (above $160 \mathrm{~g} / \mathrm{L}$ ) in $9.9 \%$ of the examined athletes, which may be associated with the impact of physical activity. It was found that the white blood cells were increased in $15.5 \%$ of the examined patients (over $\left.9.0 \times 10^{9} / \mathrm{L}\right)$. There was a normal absolute number of neutrophilic leukocytes with a predominance of rodshaped forms a normal absolute number of monocytes $(p=0.01)$. In addition, the redistribution of the number of leukocytes in the surveyed group is noteworthy, in the form of reducing the total number of band forms with the upward trend of segmented forms. Results of biochemical analysis of the blood in athletes showed that a high proportion $(23.6 \%)$ of cases of impaired phosphorus-calcium metabolism in the form of a violation of alkaline phosphatase indicators, which is probably associated with the alimentary factor. There was an increase of alanine aminotransferase in $9.9 \%$ athletes and $99.0 \%$ surveyed had normal levels of aspartate aminotransferase. Also, an increase in total bilirubin, in uric acid level and iron level was registered in $21.87 \%, 21.21 \%$, and $44.0 \%$ of the examined respectively. The total protein concentrations did not have statistically significant differences compared to the reference ranges.

Data analysis of ultrasound scan of the abdominal organs showed the presence of disturbances in $24 \%$ of cases, while these disorders were manifested by diffuse liver 
echogenicity changes in $7 \%$ of cases and pathology of the gallbladder in $17 \%$ cases. Attention is drawn to the presence of diffuse hyperechogenic changes in the pancreas in the group of athletes, which occurred in $7 \%$ of cases. The presence of space-occupying lesions (cysts) was recorded. There were no cases of lesion of the streaming system flow system or signs of biliary hypertension (Table 2 ).

Table 2. Average values of ultrasound data of the liver, pancreas and gallbladder in the group of athletes (Median Q25;Q75)

\begin{tabular}{|c|c|c|c|}
\hline Indicators & $\begin{array}{l}\text { The main group } \\
(\mathrm{n}=\mathbf{3 3})\end{array}$ & $\begin{array}{c}\text { Normal value ranges } \\
\text { (age 14-17 years) } \\
(\mathrm{n}=30)\end{array}$ & p value \\
\hline $\begin{array}{l}\text { Antero-posterior size of } \\
\text { the right lobe }(\mathrm{cm})\end{array}$ & $14.2(12.0-15.5)$ & $12.5(11.9-13.2)$ & 0.008 \\
\hline $\begin{array}{l}\text { Antero-posterior size of } \\
\text { the left lobe }(\mathrm{cm})\end{array}$ & $6.5(6.9-8.3)$ & $7.0(6.5-8.2)$ & 0.1 \\
\hline $\begin{array}{l}\text { Portal vein diameter } \\
(\mathrm{mm})\end{array}$ & $1.0(1.0-1.4)$ & $1.3(1.1-1.4)$ & 0.2 \\
\hline Common bile duct (mm) & $5.5(4.8-5.8)$ & $5.5(4.9-5.7)$ & 0.1 \\
\hline $\begin{array}{l}\text { Diffuse liver } \\
\text { echogenicity changes } \\
\text { and its contours }(\%)\end{array}$ & 1 & 0 & 0.001 \\
\hline \multicolumn{4}{|c|}{ Diffuse changes of pancreatic echogenicity (\%) } \\
\hline Hypoechoic & 0 & 0 & - \\
\hline Hyperechoic & 4 & 0 & 0.01 \\
\hline \multicolumn{4}{|c|}{ Ultrasound scan data of gallbladder } \\
\hline $\begin{array}{l}\text { Length (distance from } \\
\text { the narrowest part to the } \\
\text { bottom of the } \\
\text { gallbladder }(\mathrm{cm})\end{array}$ & $4.2-5.1$ & $6-10$ & 0.2 \\
\hline Width $(\mathrm{cm})$ & $3.4-4.4$ & $3-5$ & 0.1 \\
\hline Wall thickness $(\mathrm{mm})$ & $2-4$ & 4 & 0.01 \\
\hline
\end{tabular}

\section{Discussion}

The negative features of modern sports are due to its professionalization and commercialization, the emergence of new technical elements and even new sports, accompanied by a high risk to the health and life of athletes, the involvement of high achievements of children and adolescents in sports. The peculiarities of the influence of extreme factors on the human body are always associated with the need for maximum mobilization of functional reserves and compensatory-adaptive mechanisms, the cumulation of changes in the structure and functions of organs and systems that occur under the influence of these factors, the constant danger of disruption of compensatory-adaptive mechanisms with the subsequent development of acute or chronic " deviations "in the state of health. Over the past 1.5-2 decades, the number of cases of sudden death and serious deviations in the health of athletes has noticeably increased. At the same time, the number of these deviations is clearly related to the periods of the pre-Olympic cycle or the schedule of other world-class competitions: the closer the start, the greater and the pronounced deviations in the health status of athletes. Adaptation to extreme influences, including those characteristic of high-performance sports, is always accompanied by changes in the health status of athletes [9-10]. Compensatory mechanisms manifested in these cases are often formed due to the reserves of the structure and function of organs and systems that are not directly related to the achievement of the final result. These compensations can undergo a reverse development (animmunoglobulinemia, recorded in some athletes at the peak of 
their athletic form, or have a persistent non-transient nature (impairment of the structure and function of the kidneys in chronic ischemia of the renal parenchyma, which develops as a result of blood redistribution during physical exertion. Many functional indicators in highclass athletes come out For example, the resting cardiac index in stayers is at a level characteristic of the clinical picture of heart failure (less than $2.11 / \mathrm{min} / \mathrm{m} 2$ ), the heart rate makes one suspect complete AV block (less than 40 per minute ), only $30 \%$ of athletes have an electrocardiogram that does not have deviations from the norm, etc. Thus, "absolute" health (if we mean the criterion of "norm") as a criterion for admitting an athlete to participate in the training process and competitions is fiction, an ideal unattainable under the conditions of stress in the modern professional new and Olympic sports [11-12].

Assessing the state of health and physical development of adolescent athletes, in our study, who are engaged in single combat, on average about 8 years old, the majority have an average level of harmony of development, a high level of physical fitness, according to hand dynamometry. The results of the Harvard step test showed that two-thirds of the examined have an adequate level of physical performance with good recovery ability Spirometer indicators confirmed to the age norms.

The obtained data about very low level of physical performance with a normal or slow recovery period after exercise in $33.4 \%$ surveyed was explained by the presence of the cardiovascular system functional disorders via ECG - sinus tachycardia, right bundle branch block, episodic ventricular tachycardia and impaired repolarization of metabolic nature.

Detected changes in phosphorus-calcium metabolism, leukocytosis with segmented shift, increase of alkaline phosphatase, uric acid and serum iron, changes of the liver echogenicity, pancreas and gallbladder are probably associated with an alimentary factor [13-16].

Repeated in-depth examination using advanced examination methods will allow assessing the functional state of the selected group of athletes in the process of implementing the training program in dynamics.

\section{Conclusion}

The revealed changes in the cardiovascular system of adolescent combat athletes require detailed study, drawing up individual training schedules for athletes and careful medical support.

Taking into account the presence of violations of some biochemical parameters of the blood of athletes, it is necessary to study in detail the nature and hygiene of nutrition of adolescents, with the subsequent correction of the diet.

The work was performed within the funds allocated for the implementation of the state assignment of the institute.

\section{References}

1. D. Nikitjuk, S. Chava, G. Azizbekjan, The estimation of morphological characteristics in sportsmen of different specialization and qualification. Bulletin of Anthropology, 20, 147-151 (2011) doi.org/10.18499/2225-7357-2018-7-4-9-19

2. D. M. Berkelmans, V. J. Dalbo, C. O. Kean, Heart Rate Monitoring in Basketball: Applications, Player Responses, and Practical Recommendations, J Strength Cond Res. 32(8), 2383-2399 (2018) doi: 10.1519/JSC.0000000000002194 
3. H. S. Martins, D. D. Lüdtke, J. César de Oliveira Araújo, Effects of core strengthening on balance in university judo athletes, J Bodyw Mov Ther, 23(4), 758-765 (2019) doi: 10.1016/j.jbmt.2019.05.009

4. G. K. Myburgh, S. P. Cumming, M. Coelho E Silva, Growth and maturity status of elite British junior tennis players, J Sports Sci 34(20), 1957-64 (2016) doi: 10.1080/02640414.2016.1149213

5. M. Nekrasova, V. Sheyko, Investigation of the factors of the risk of forming the occupational stress in sportsmen. In the book: Profession and health. Materials of the 2nd International Youth $\quad$ Forum, 183-188 (2018) https://docviewer.yandex.ru/view/0/?page=1

6. C. Kenn, A. May, Ergometry - Step by Step Dtsch Med Wochenschr, 143(17), 12521257 (2018) doi: 10.1055/s-0043-111859

7. I. N. Kostikiadis, S. Methenitis, A. Tsoukos, The Effect of Short-Term Sport-Specific Strength and Conditioning Training on Physical Fitness of Well-Trained Mixed Martial Arts Athletes, J Sports Sci Med. 14, 17(3), 348-358 (2018)

8. H. Semper, P. Kühnelt, P. Seipp Cardiopulmonary Exercise Testing-Step by Step Dtsch Med Wochenschr, 144(1), 39-45 (2019) doi: 10.1055/a-0600-9233

9. T. R. Snedden, J. Scerpella, S. A. Kliethermes, Sport and Physical Activity Level Impacts Health-Related Quality of Life Among Collegiate Students, J Health Promot, 33(5), 675-682 (2019) doi: 10.1177/0890117118817715. Epub 2018 Dec 26.

10. M. S. Golovin, M. S. Golovin, R. I. Aizman, Audiovisual Stimulation Modulates Physical Performance and Biochemical and Hormonal Status of Athletes, Bull Exp Biol Med., 161(5), 638-642 (2016) doi: 10.1007/s10517-016-3474-3

11. J. Suzic Lazic, M. Dekleva, I. Soldatovic, Heart rate recovery in elite athletes: the impact of age and exercise capacity, Clin Physiol Funct Imaging, 37(2), 117-123 (2017) doi: 10.1111/cpf.12271

12. S. Sharma, J. A. Drezner, A. Baggish, International recommendations for electrocardiographic interpretation in athletes, Eur Heart J. 21, 39(16), 1466-1480 (2018) doi: 10.1093/eurheartj/ehw631

13. P. E. Adami, M. R. Squeo, F. M. Quattrini, Pre-participation health evaluation in adolescent athletes competing at Youth Olympic Games: proposal for a tailored protocol, Br J Sports Med., 53(17), 1111-1116 (2019) doi: 10.1136/bjsports-2018099651

14. J. S. Coll, Y. C. Martín, M. S. Puente, Comparative study of the variables of physical fitness and health among young athletes and sedentary males, Nutr Hosp. 5, 35(3), 689-697 (2018) doi: 10.20960/nh.1502

15. H. C. Huang, W. L. Wu, Y. K. Chang, Physical fitness characteristics of adolescent wushu athletes, J Sports Med Phys Fitness., 58(4), 399-406 (2018) doi: 10.23736/S0022-4707.16.06748-7

16. A. J. Walker, B. A. McFadden, D. J. Sanders, Early Season Hormonal and Biochemical Changes in Division I Field Hockey Players: Is Fitness Protective? J Strength Cond Res, 34(4), 975-981 (2020) doi: 10.1519/JSC.0000000000003492 